\title{
American College of Cardiology/American Heart Association Lesion Complexity Class
}

National Cancer Institute

\section{Source}

National Cancer Institute. American College of Cardiology/American Heart Association Lesion Complexity Class. NCI Thesaurus. Code C100032.

A classification system for coronary stenosis based upon characteristics that influence the difficulty of percutaneous coronary revascularization. (ACC) 